\title{
Public Sustainable-Energy Requirements and Innovation in UK PFI School Projects
}

\section{Abstract}

In a bid to understand the relationship between public-sector clients' sustainable-energy requirements and innovation, this paper describes a study examining the requirement-development process in four Private Finance Initiative (PFI) school projects. A case-study approach was adopted to enable a greater understanding of the public-sector clients' activities at the front end of the design process, particularly focusing on requirement-identification and the effect of the requirement on private-sector actors' pursuit of an innovative sustainable design. The findings have shown that incentive effects of the requirements are often weak in PFI projects, particularly in relation to the requirement's specificity and achievability, the inability of requirements such as BREEAM to promote energy efficiency, and the low weighting of environmental sustainability on PFI bid-evaluation criteria. Taken together, these results offer insight into public authorities in relation to the necessary conditions for the use of requirements as an effective contractual mechanism to encourage innovation for sustainable energy.

\section{Keywords:}

Public-sector client; sustainable-energy requirements; design process; sustainable-energy innovation; Private Finance Initiative (PFI); schools. 


\section{Introduction}

The UK, along with other developed countries, is dependent on energy for its development and prosperity. Buildings account for the largest overall proportion of UK energy consumption (45\%) and are responsible for substantial $\mathrm{CO}_{2}$ emissions, with detrimental effects on the environment and the world's climate (Yudelson, 2008). The UK government is committed to a legally binding target to reduce $\mathrm{CO}_{2}$ emissions by $80 \%$ (compared with the 1990 levels) by 2050 (Department of Energy and Climate Change, 2008). Among the key strategies advocated by the government to achieve such a significant reduction in $\mathrm{CO}_{2}$ emission is technological innovation (Cabinet Office, 2002; Stern, 2006; DEFRA, 2007). Innovation is expected to play a major role in dealing with the issue because, as Thalmann (2007) argues, 'technological change supports all the hopes for painless reduction in greenhouse gases emissions' (Thalmann, 2007). The Stern Review on the economics of climate change also stresses that 'policy to support innovation and the deployment of low-carbon technologies will be a key response to mitigating climate change' (DTI 2007, p. 216; Stern, 2006).

The role of the construction industry is paramount in driving the technological innovation needed to support a low-carbon built environment (Whyte and Sexton, 2011). In particular the public sector, as a major construction-industry client, can play a significant role in promoting sustainable-energy innovation (SEI) that reduces the negative impacts of energy use, by increasing energy efficiency, or utilising new means of renewable energy generation (Badi and Pryke, 2015). Public procurement has been promoted as a powerful vehicle to drive innovation (e.g. Dalpé et al., 1992; Edquist, 1998; Edler et al., 2005; Edler and Georghiou, 2007). The Confederation of British Industry (CBI) argues: 'Public procurement is the biggest single customer-side driver that could be harnessed to catalyse business innovation activity' (CBI, 2006: 2). Construction clients are increasingly viewed as 'change agents' (Brandon and $\mathrm{Lu}, 2008$ ) and their enormous capacity to exert influence towards innovation is well 
accepted to the extent that 'current policy in the UK identifies the experienced client as the main institutional leader in stimulating construction innovation' (Winch, 1998, p. 276).

The client's requirement is particularly found to be one of the main determinants of innovation in construction projects (Kumaraswamy and Dulaimi, 2001; Dewick and Miozzo, 2004; Barrett and Sexton, 2006; Richardson and Lynes, 2007; Hartmann, 2008). The role of the client's requirement in driving innovation is mostly important in the case of innovation for environmental sustainability (Bossink, 2004). Anderson et al. (2004) argue that environmental concerns expressed by a variety of stakeholders are among the chief pressures for change in the construction industry. However, a number of research studies have identified that environmental innovations are still in their 'embryonic' stages (Kelly, 2008). Orstavik et al. (2015) and Whyte and Sexton (2011) call for further research in order to improve the understanding of innovative processes in construction projects, while Häkkinen and Belloni (2011) and Haugbølle and Boyd (2013) argue that the role of the client in construction innovation requires more careful examination than has thus far been afforded.

The focus of this study is on the role of the client requirement in driving innovation in the Private Finance Initiative (PFI) project delivery model; a type of Public Private Partnership (PPP). In PFI projects, a consortium of private-sector firms, known as the ProjectCo, assumes the responsibility of designing, constructing, financing, and operating an infrastructure facility. In addition, the PFI consortium is contracted to provide the public services on a long-term contractual basis (up to 30 years) with the relevant government body ${ }^{\mathrm{i}}$. However, the front end in PFI is often lengthy and little is understood about its nature in the context of the PFI process. How the public-sector client requirement is developed, incorporated, and how it may interplay with innovation for sustainable energy remain questions barely explored. In particular, two research questions are posed: 
1. How is the public sustainable-energy requirement developed? And what, if any, are the barriers faced by the parties concerned for its successful identification?

2. How is the public sustainable-energy requirement translated into SEI? What are the characteristics of the sustainable-energy requirement that are more conducive to SEI?

It was to investigate these questions that this in-depth study of four PFI school projects was undertaken within the UK Building Schools for the Future (BSF) programme, a government schoolrenewal scheme. BSF was introduced in 2004 by the Department for Education and Skills' (DfES) with the aim to renew the aging UK school estate ${ }^{\mathrm{ii}}$ by rebuilding or refurbishing every secondary school in England over a period of approximately 10-15 years, subject to future public-spending decisions ${ }^{\text {iii. }}$. The funding allocated was based on enabling up to $50 \%$ of the gross floor area of a Local Authority's school estate to be new-build, $35 \%$ major refurbishment, and $15 \%$ minor refurbishment (DfES, 2005). The 50\% new-build element was delivered through PFI contracts as it was found to represent best value to the public sector (DfES, 2005). The goal of the programme was to promote reform in the organisation of schooling, teaching, and learning and to drive transformational educational change (DfES, 2004). BSF has also been actively seeking to embed sustainability (House of Commons, 2007). The need for SEI in school buildings is reinforced by the fact that school buildings are responsible for about $2 \%$ of greenhouse gas emissions in the UK. This is equivalent to $15 \%$ of the national public-sector emissions (DCSF, 2010). In order to address the need for sustainable development in school buildings, the Department for Children, Schools, and Families (DCSF) developed challenging targets for sustainable school buildings that supported the wider government policies on low-energy/carbon buildings, culminating in the ambitious target that all newly built schools were to be 'zero carbon' by 2016 (DCSF, 2007 iv). Although this target was later delayed to 2019 to match the EU Energy Performance of Buildings Directive, there was clearly a commitment by the UK government to significantly reduce carbon emissions of new school buildings in the near future. 
The main contribution of this research is to provide a greater understanding of public-sector clients' activities at the design's front end of sustainable PFI school projects and how the sustainable-energy requirements that they develop influence the design process and the pursuit of innovation for sustainable energy by private-sector actors. By doing so, the study elaborates on two distinct stages in the innovation-management process (Dewulf, 2013): (1) sustainable energy at the design front end as the client's requirement, and (2) SEI at the design-development stages. The study also expands previous research on public procurement of innovation (e.g. Dalpé et al., 1992; Edquist, 1998; Edler et al., 2005; Edler and Georghiou, 2007) by empirically examining the role of public demand, in the form of the UK government's PFI procurement policy, in supporting innovative sustainable energy solutions. By doing so, the study may lead to a greater understanding of how the PFI project delivery model can work to encourage innovation in the construction industry and to the growth or even creation of markets for innovative sustainable products and services.

The paper begins by introducing the concepts of innovation, environmental innovation, and SEI. This is followed by reviewing the literature on clients' front-end design activities and innovation. The third section provides information on the research method and discusses issues related to research design, data collection, and analysis. In the fourth section some contextual background is provided to the case-study projects, while the fifth section describes the findings in relation to the issues involved. A final conclusion outlines the contributions of the research and the implications for sustainable-energy requirement management in public-sector projects. 


\section{Conceptual Underpinnings}

\section{Sustainable-Energy Innovation (SEI)}

Early work by Schumpeter (1980) defines "innovation" as the introduction of an irreversible change in the way of doing things that ultimately results in economic gain. Schumpeter (1980) also distinguishes between five types of innovation: (1) introduction of a new product or a qualitative change in an existing product; (2) process innovation new to an industry; (3) opening of a new market; (4) development of new sources of supply for raw materials or other inputs; and (5) changes in industrial organisation (Schumpeter, 1980). Innovations that reinforce existing products or processes and utilise current knowledge and experience are termed 'incremental' whilst those bringing about disruptive changes in a specific field and result from novel approaches to understanding and problem-solving are referred to as 'radical' (Slaughter, 1998). SEI is a particular subset of environmental innovations - also known as "eco-innovations". The term 'SEI' is used in this research to represent 'novel technological products or solutions that are successfully integrated into building's design strategies in order to prevent or substantially reduce the negative impacts of energy use by increasing energy efficiency, or utilising new ways of renewable energy generation'” (Badi and Pryke, 2015: 411).

\section{Development of the Client's Requirement}

Several conceptual approaches exist that attempt to classify construction-industry clients, with some focusing on the level of experience that the client has with construction while others focus on the level of client complexity. Early work by Higgin and Jessop (1965) differentiates between sophisticated and naive clients, based on their past experience with construction. Darlington and Culley (2004) distinguished between the identifiable and the virtual customer, the former having a specific design 
problem that can be discussed directly with designers, while the latter represents a complex and multifaceted group of individuals with evolving requirements that need to be systematically captured as they emerge (Ulrich and Eppinger, 2000). Bahill and Dean (1999) argued that the term "client" should include all stakeholders with the power to impose requirements on the end product, while Kamara et al. (2002) postulated that the client is the entity responsible for representing the diverse interests of those stakeholders and ensuring their incorporation in the delivery of the project. In the case of public-sector organisations, such as Local Authorities, they can be classified as complex virtual clients as they need to sufficiently represent various stakeholder groups as well as wider societal needs. The challenge in the case of complex and virtual clients is to provide clear and accurate design information despite the complexity of their organisational setting ( $\mathrm{Yu}$ and Shen, 2013).

The client's requirements, commonly known as "the brief", or "the Output Specification" in PFI projects, is the first step that clients take when engaging with the construction industry, representing their aims, objectives, and constraints in relation to the project quality and performance (Lindahl and Ryd, 2007; Tzortzopoulos et al., 2006). The brief may take the form of a simple statement, or be a set of detailed specifications (Yu and Shen, 2013). The early requirement-identification stage, often termed the 'fuzzy front end' (Smith and Reinersten, 1998) has been considered one of the most important stages for project success, innovation, and performance (Hobday, 1998; Hansen and Rush, 1998). The development of the client's requirement is, however, considered a difficult process and a number of studies have underlined two particularly challenging issues in the process of requirement identification and management: (1) availability of an adequate knowledge base, and (2) effectiveness of stakeholder involvement, as will be discussed below. 


\section{Availability of an adequate knowledge base}

As Yu et al. (2010) pointed out, construction-industry clients may adopt different attitudes towards the development of their requirements. Consequently the comprehensiveness of the requirements often depends on the experience of clients. Experienced clients are likely to develop highly detailed requirements, while "novice" clients tend to avoid the process in its entirety. Kamara et al. (2002) highlighted the difficulties faced by clients in understanding the complexity of the building as a whole at the early inception stages, thus resulting in incomplete and inconsistent requirements and specifications. They thus argued that briefing is better conceptualised as a dynamic process that should continually capture the client's requirements as they progressively develop. Barrett and Stanley (1999) also claimed that the limited clarity of the requirement may lead to potential misunderstanding and misinterpretation by the design team. The amount of time allocated to the briefing process is also critical, as inadequate resources allocated to this important stage can result in poorly formulated requirements and, ultimately, the client's dissatisfaction (Othman et al., 2005).

\section{Effectiveness of stakeholder involvement}

Defining the construction client as a 'configuration of stakeholders', Newcombe (2003) underlined the importance of identifying a wide range of project stakeholders and understanding their expectations. Tzortzopoulos et al. (2006) also stressed the necessity for the client organisations to identify all stakeholders that need to be involved in requirement identification. The limited involvement of a large number of stakeholders, including end users, in the development of the requirement would result in a building that is inadequate in use (Amstel et al., 2015). The multiple stakeholders involved also often pursue diverse and sometimes conflicting interests and objectives. Thus prioritising the requirements from different stakeholders may represent a significant challenge to the client organisation (Darlington and Culley, 2004; Tzortzopoulos et al., 2006). 


\section{Translation of the Client's Requirement and Innovation}

A large and growing body of knowledge in product development and construction innovation has underlined the importance of the client's requirement in encouraging innovation (Hobday, 1998; Hansen and Rush, 1998; Edler and Georghiou, 2007). In particular, three characteristics of the client's requirement have been argued as supporting innovation, being the requirement's (1) novelty, (2) flexibility, and (3) incenitvisation, as will be discussed below.

\section{Novelty of the requirement}

The novelty of the client's requirement is often associated with innovation. Early work by Tatum (1984) identified that challenging engineering, construction, and schedule requirements are among the main conditions that foster construction innovation. Nam and Tatum (1992; 1997), Barlow (2000) and Seaden and Manseau (2001) also emphasised that 'demanding' clients are likely to stimulate innovation in the projects they commission. Miozzo and Dewick (2002) and Bossink (2004) suggested that innovation is driven by governmental clients guaranteeing markets for innovative products and services and subsidising new applications and materials. Clients can also increase the pressure on project participants to improve buildings' lifecycle performance, durability, and future flexibility and adaptability (Gann and Salter, 2000; Qi et al., 2010) and demand higher standards and specifications (Barlow, 2000; Seaden and Manseau, 2001; Anderson et al., 2004; Lam et al., 2011). Blayse and Manley (2004) proposed that procurers can exert significant pressure on the construction industry to develop novel products and technologies by demanding standards far too difficult for existing technologies to meet, encouraging the pursuit of innovation. This is particularly important in the case of sustainability innovations with which the client's demand for higher environmental standards and specifications can force producers to improve their environmental performance (Kemp and Foxon, 2007; Ozorhon, 2012). 


\section{Flexibility of the requirement}

The second characteristic closely associated with innovation is the requirement's flexibility, or what is often termed 'design freedom' (Heavisides and Price, 2001; Leiringer, 2003). This is closely linked to outcome-based requirements, as opposed to input-based, as effective drivers for innovation (Heavisides and Price, 2001; Johnson and Medcof, 2007). Service specifications are often either input- or output-based. Input specifications, sometimes termed "prescriptive" specifications, are defined by Heavisides and Price (2001) as 'documents that traditionally detailed the exact requirements of the service, the likely hours required to provide that service and the exact inputs needed to replicate or improve the existing service provision' (p. 344). They further argue that this form of specification is being challenged by Output Specification, also termed "performance-based" specification. Contrary to input specification, which focuses on "how" a facility should be delivered by specifying the exact dimensions, materials, and workmanship, an Output Specification concentrates on "what" is required in terms of accommodation standards and services (Robinson and Scott, 2008). Outputs are defined as 'the results of activities that can be clearly stated or measured and which relate in some way to the outcomes desired' (HM Treasury, 2015: 13) ${ }^{\text {vi }}$. Government guidance advocates that output-based specification provides more scope for innovation and flexibility in service delivery than traditional input-based specification (HM Treasury, 1999). Gann et al. (1998) and Tawiah and Russell (2008) also maintained that output-based building specifications are progressive and work to encourage innovation. The key advantage of output-based specifications rests in their ability to allow design novelty in terms of choice and scope for decision preferences towards cost, quality, and process (Heavisides and Price, 2001).

\section{Incentivisation mechanisms}

The third element that closely associates the client's requirements with innovation is the incentivisation mechanism included in the requirement for the pursuit of novelty beyond existing 
practices. Lenard and Eckersly (1997) and Winch (1998) suggested that the level of innovation that occurs on construction projects is highly dependent on contractual incentives to encourage innovation, while Bresnen and Marshall (2000) and Eriksson and Westerberg (2010) advocate that in order to encourage the supply side to achieve exceptional results in terms of certain performance criteria, incentives should be linked to specific aspects of project objectives. Among such mechanisms are the contract-assessment criteria used by clients in selecting their service providers, particularly in the case of projects that are procured competitively. Kadefors et al. (2007), in a study examining the contractor-selection procedures in Swedish partnering projects and how these relate to service innovations, have emphasised the need for procurers to make a conscious attempt to encourage innovation and commitment among potential bidders. In the case of environmental sustainability, Sporrong and Bröchner (2009) examined the choice of contract-award criteria in 93 Swedish municipal clients and how these procurement procedures provided incentives for environmentally sustainable design-management. Their findings suggested that sustainability-related criteria are implemented only to a limited extent in tender assessments, supporting the call for more effective provider-selection methods in order to strongly encourage sustainable design practices in projects.

In summary, the conceptual perspectives above underline the importance of three characteristics that public sustainable-energy requirements should represent in order to encourage the pursuit of SEI. Greater novelty of the requirement is needed, as the innovative organisation's main concern is the extent to which the innovation meets the criteria set for the specific context, while maintaining the flexibility needed for innovation. Novelty and flexibility should be supported by incentivisation mechanisms in the form of effective sustainable selection criteria that encourage the pursuit of innovative sustainable energy solutions beyond existing practices. In the next section, the methodology adopted to examine the identified issues in four PFI school projects will be described. 


\section{Research Method}

\section{Case-study Approach}

Adopting a qualitative research lens, an explorative case-study approach was considered the best suited for this research for its ability to examine real-life situations and provide a rich insight into a research object (Miles and Huberman, 1994; Flyvbjerg, 2006). A case is defined as a formally documented PFI construction project and the study adopts a "multiple case" design approach, preferred over a "single case" because multiple cases support the triangulation of evidence and data sources for more rigorous research (Eisenhardt and Graebner, 2007; Yin, 2014). Following a purposive sampling strategy, four new-build BSF PFI school projects were selected for investigation, subject to a set of criteria to ensure comparability as follows:

- The project was to be part of the Local Authority's "sample" schemes, i.e. the project should be among the initial projects that the Local Authority went to market with when procuring its BSF programme. This was decided to ensure that the project followed the typical BSF PFI development process.

- The project was to include evidence of implementing SEI. This was the criterion in selecting three of the case studies (Case Studies 1, 3, and 4). The fourth case study was selected as it showed no evidence of SEI (Case Study 2). The examination of innovative as well as noninnovative projects was pursued to facilitate a heterogeneous sample; the technique also known as 'Maximum variation sampling' (Flyvbjerg, 2006), which allowed the capture of a wide range of perspectives relating to the conditions under which SEI is implemented, or otherwise, and assisted the researcher in identifying common themes that were held consistently across the case-study projects. In order to verify the nature of the solutions 
implemented and whether or not they could be considered innovative, extensive review of the national press and trade journals was undertaken. In addition, the case-study projects and their innovative solutions were described to an independent heating and ventilation (HV) design expert to confirm whether the SEIs implemented could be considered as novel changes from standard practice.

- To control as much as possible for the impact of contextual factors on innovation outcomes,

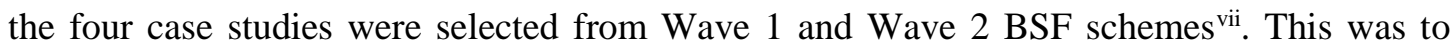
ensure that the projects were subjected to the same policy and economic environment and followed the same BSF documentation and national legislation.

- In order to take account for both memory retrieval problems in the analysis of past events and to support the accuracy of the data collected (Bernard et al., 1984), the four projects were to have been recent projects. At the time data collection was conducted, between April 2009 and May 2010, three of the case-study projects, i.e. Case Studies 2, 3, and 4, were being constructed on-site when the researcher established first contact with the projects. Case Study 1 was operational for a few months. The more recent time "window" to what the case-study participants were reporting on may have increased the accuracy of their responses (Bernard $e t$ al., 1984).

Table 1 provides a brief outline of each case study, including the location, value, BSF Wave, and the main SEIs implemented. Pseudonyms are used to represent the cases in order to maintain their anonymity.

*******INSERT TABLE 1 ABOUT HERE ****** 


\section{Data Collection}

\section{Case-study participants}

The unit of analysis in this study is the PFI project and the main project actors involved within both the Local Authority and the ProjectCo served as the primary sources of data. The research participants were chosen based on their knowledge and involvement in the project (Eisenhardt and Graebner, 2007). In order to determine the key actors within each stakeholder group, the study benefitted from Dair and Williams' (2006) identification of key stakeholders influencing the development of sustainable brownfield sites. Applying the identification to the PFI project context, Table 2 lists the key actors that were selected as key sources of data.

******INSERT TABLE 2 ABOUT HERE $* * * * * *$

Based on the individual composition of each PFI project and a comprehensive discussion with a key Local Authority/ProjectCo informant, the main players in each stakeholder team were identified and selected as key interviewees within each case setting. Involving project participants in the study was largely promoted by using key individuals with the Local Authority and/or the ProjectCo as high-level sponsors for the research. The number of key informants on each stakeholder team depended on the role of that stakeholder and the number of individuals identified as important contributors by other project members. At least 12 interviews per individual BSF PFI construction project were considered adequate to ensure the desired information-richness of the case study. A total of 50 interviews were conducted.

\section{Interviews and Units of Assessment}

Face-to-face semi-structured interviews were the method used for data collection. A Case Study Interview Protocol was developed based on the study's Units of Assessment (UofAs). The UofAs 
were conceptualised from the original research questions and subsequently informed the interview questions. This approach involved a set of pre-specified open-ended questions which were posed to the interview participants, who were then given the liberty to freely frame their response to the question. Further elaboration on the interviewees' responses was sought by the researcher, asking additional questions. The approach was beneficial in ensuring a clear and reliable structure across all the interviews conducted and provided the researcher with the ability to control the flow of the conversation, while also maintaining the flexibility needed for the participants to fully express their views and build effective interviewee/interviewer rapport (Mallozzi, 2009). On average, each interview lasted between 60-90 minutes and was conducted at the interviewee's premises, often in a boardroom or company meeting room. Each interview commenced with a brief commentary on the project and the SEIs implemented. This was effective in establishing common understanding among participants of what actually constitutes an SEI. The Case Study Interview Protocol included two separate sections to be completed by either Local Authority or ProjectCo actors. Details on the developed qualitative definitions of the case study's UofAs and the corresponding interview questions are provided in Table 3.

******INSERT TABLE 3 ABOUT HERE

With consent from each of the informants, all interviews were recorded and later transcribed verbatim by the researcher and saved as Word files. A one-hour interview often produced about 20-25 pages of single-spaced text. The recording of interviews ensured the accuracy of the data and eliminated the loss of any detail before the analysis. Although transcribing the tape-recorded data was timeconsuming, the process provided the opportunity for the researcher to be more "intimate" with the data, reflecting, sketching, and building concepts and connections as she listened, prior to exploring the transcribed textual data in detail during the data analysis stage that followed. 


\section{Analysis}

The preliminary analysis of the interviews' textual data began early during the data collection stage after a few interviews had been completed and ran almost concurrently as the data was collected. This was effective in indicating the point when "saturation" of the data was achieved; with the data initially difficult to organise and categorise into concepts, but as the sample grew in size, replication of categories emerged, supporting conceptualisation and abstraction (Harwood and Garry, 2003). The analytical process began with the researcher carefully reading through each interview transcript and making frequent notes in the margins to underline important statements and identify ways of categorising, i.e. coding the data: "Achievability of the Requirement" for example, or "Specificity of the Requirement". A tabular thematic framework was used to support the categorisation and summary of the data, with headings and categories pre-listed reflecting the main UofAs examined (refer to Table 3), as well as any new themes emerging from the reading of the interview transcripts. The textual data was extracted manually from the interview transcripts, first as complete segments (statements) cut-and-pasted from the interviewee's answers to each interview question, and later summarised in a series of four charts corresponding to each case study. This data reduction and display was used to explore the responses of all the interview participants within the main UofAs, looking for similarities and differences in responses, and supporting in-case analysis. Tabular displays were also subsequently used to conduct cross-case comparative analysis as shown in Table 4, which helped in underlining the main issues that would hold consistently across the UofAs.

*******INSERT TABLE 4 ABOUT HERE ******* 


\section{Findings}

This section introduces the multiple case-study findings divided into two sections. The first section examines the development of the sustainable-energy requirements within the four Local Authorities. The second section explores how private-sector actors have translated the sustainable-energy requirements they have been presented with and their perception of the incentive effects of the requirement on their pursuit of innovation for sustainable energy.

\section{Development of the Sustainable-Energy Requirement}

The four Local Authorities' BSF programmes were managed by Core BSF Management Teams that included project directors, project managers, solicitors, and administrators. The teams were often supported by external technical, design, legal, and financial advisors. The four Local Authorities saw BSF as an opportunity to break the cycle of educational underachievement in their areas and offered

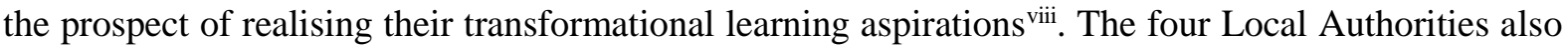
saw the pursuit of a sustainable solution as an opportunity to showcase their commitment to the issue and understood the need for good green credentials alongside such a substantial investment as BSF. Table 5 provides a summary of each Local Authority's environmental requirement (including sustainable energy) as part of their Output Specification and lists the weighting given to environmental sustainability as part of the bid-evaluation criteria.

******INSERT TABLE 5 ABOUT HERE ****** 


\section{Availability of an adequate knowledge base}

A number of studies have highlighted the importance of clients' competence and understanding of their objectives for successful innovation (Nam and Tatum, 1997; Barrett and Stanley, 1999). However, as the four Local Authorities were among the first to be invited to BSF, the Core Teams experienced some difficulties in the drafting of the sustainable-energy requirement within the Output Specification (Table 4, UofA.1) due to the unfamiliarity of the programme for the four Local Authorities, lack of expertise in procuring through the PPP or PFI routes, and limited knowledge about the implementation of sustainability within the BSF context. In addition, the schools' ability to effectively contribute to discussions about sustainability was seen to be limited by their lack of technical knowledge about the subject.

To support Local Authorities and schools in drafting their requirements, private technical and design advisors were appointed as well as external advisors for legal and financial issues. The client design advisor acted from the inception of a BSF project through to its completion, performing a range of tasks to help ensure that the schools delivered are of the highest quality. Technical advisors coordinated the technical aspects of BSF projects. They advised on all the technical detail such as specifications and construction standards. The Sustainability Criteria included in the Output Specification were often developed by the Technical and Design Advisors in collaboration with the sustainability expertise within the Local Authorities and Core BSF Teams. Advisors were also involved during engagement with bidders and in evaluating bids. In addition, the Output Specification was required to follow the standard documents provided by Partnerships for Schools (PfS), the public body responsible for the delivery of the programme. The need for BSF to meet national standards and deliver government policy meant that service specification within the programme was largely directed by guidance and required an element of control (DfES, 2005). However, while this standardisation by PfS may have provided an established starting point across the BSF programme, the findings of HGS (Case Study 3) suggested that this has resulted in generic requirements that did not reflect the 
specificity of the school sites. The clarity of the requirement was also restricted by the large amount of information included in the Output Specification which led to targets being duplicated and a lack of a clear hierarchy of the Local Authority's priorities (HGS- Case Study 3).

\section{Effectiveness of stakeholder involvement}

Under BSF, the four schools enjoyed a great deal of power as they took part in writing their requirements, in engagement with ProjectCo actors, and in evaluating the bids. This was supported by BSF engagement teams that worked to develop effective relationships between schools and Local Authorities, representing a significant improvement from early PFI school deals where no amount of consultation was undertaken with schools (Edwards and Shaoul, 2003). However, the case-study findings (Table 4, UofA.2), have shown that the effectiveness of internal stakeholder involvement has varied considerably between the four Local Authorities. On HGS (Case Study 3), the Core Team created a Technical Team responsible for putting together the Output Specification, including the sustainability requirements. On the Technical Team sat the Head of the Sustainability Unit, Senior Energy Manager, as well as the Senior Planning Officer. The role of the Sustainability Unit was evidently important during the development of the Output Specification and the Unit worked closely with the Core Team and acted as the primary source of sustainability knowledge and expertise to the Technical Team, as well as to other stakeholders within the Local Authority. On BWS (Case Study 4) commitment to sustainability cascaded all the way through from senior councillors to members of the Core Team. The pursuit of a sustainable solution was fundamentally driven by the Core Team and particularly by the LA Design Manager who ensured that sustainability formed an important part of the Local Authority's vision and requirement. The City Council Planning Department also took the lead on driving a $20 \%$ on-site renewable energy generation on all school sites.

Conversely, the initial consultation period leading to the development of the Output Specification was tightly managed by the Core Teams on both BEC (Case Study 1) and SVC (Case Study 2). On BEC 
(Case Study 1) the Core Team enlisted the help of the Council's in-house Sustainable City Team which advised the Core Team concerning sustainability issues and was involved in the visioning process, the writing of the sustainability requirement, engagement with bidders, as well as in bids' evaluation. However, the Sustainable City Team had limited communication with other parts of the Local Authority during the consultation leading to the development of the Output Specification, such as the Energy Management Unit and the Planning Department, and this lack of open consultation was attributed to the project-management mentality of the Core Team and their focus on freezing the design early to reduce risk exposure. Consequently, this limited the exploration side of the consultation and restricted the ability of stakeholders to appraise different sustainability options. A similar approach was also observed on SVC (Case Study 2) as the Director of Education at the time decided not to involve other parts of the Local Authority and to work autonomously with the Core Team in developing the Output Specification. The decision to not involve other parts of the Local Authority was largely due to a lack of adequate funding and resources to secure this involvement. This limited engagement of key internal stakeholders on BSF is a significant obstacle for SEI as successful identification of innovative requirements requires the appropriate investment of time and the reconciliation of the expectations, needs, and constraints of a large and diverse set of stakeholders (Tzortzopoulos et al., 2006).

\section{Translation of the Sustainable-Energy Requirement and SEI}

The sustainable-energy requirements were made clear to potential bidders when the Official Journal of the European Union (OJEU) notice was posted, advertising the project to potential bidders. The Invitation to Participate in Dialogue (ITPD) documentation included, among other documents, the Output Specification which outlined the needs of the public-sector client and the responsibility of the private-sector partner. ${ }^{\text {ix }}$ It also outlined the bid-evaluation criteria, which comprised mandatory items such as Value for Money (VfM) and design compliance, as well as desirable criteria such as innovation and sustainability (PfS, 2006). ProjectCo actors across the four case study projects agreed 
that this is the most important stage to integrate sustainability, as it allowed bidders enough time to develop their solutions in advance of actual tendering and it improved the quality of the solutions proposed. This section examines private-sector actors' perception of the incentive effects of the sustainable-energy requirement on their pursuit of innovation for sustainable energy. The findings will be discussed under three headings: the novelty of the requirement, the flexibility of the requirement, and the incentivisation mechanisms provided.

\section{Novelty of the sustainable-energy requirement}

The novelty of the client's requirement is often seen to encourage innovation (Blayse and Manley, 2004). The multiple case-study findings identify an important dimension of the novelty of the requirement - its 'achievability', characterised by its sensitivity to existing technological and financial constraints (Table 4, UofA.3). Achievability concerns pertaining to the sustainable-energy requirement were found to increase the pressure on ProjectCo actors and to restrict the innovative interpretation of the requirement. This was particularly identified on HGS (Case Study 3) and SVC (Case Study 2). On HGS (Case Study 3) the requirement originally submitted was $10 \%$ on-site renewable energy generation, however, the Local Authority decided midway through the bidding process to increase the requirement to $20 \%$. The target was ambitious at the time and was pushing the boundary of what could be achieved for sustainable energy. According to the Project Architect, "the local authority wanted to be the best in the London'. This change was perceived by ProjectCo actors as a considerable challenge and it highly complicated the design process. The ProjectCo actors were frustrated by the Local Authority actors' lack of appreciation of budget constraints and their limited understanding of the effect of such a change in the requirement on the ProjectCo's supply chain delivering the project and its overall profitability. This was also identified on SVC (Case Study 2), the project that did not include any implemented SEI. ProjectCo actors were increasingly frustrated by the Local Authority's sustainable-energy requirement of zero-carbon schools, which was perceived to be 'unrealistic', both technically and financially at the time. Among Local Authority representatives 
there was a perceived general lack of understanding of the financial and technological limitations of such a requirement. The ProjectCo was ultimately forced to derogate from the requirement on the BSF PFI contract.

An important distinction could be made between the change of requirement midway through the process on HGS (Case Study 3), and the introduction of the novel operational carbon target on BWS (Case Study 4). Case Study 4 presented a special regulatory context, in that it benefitted from the introduction of the government's Carbon Funding and was awarded the extra funding of $£ 50 / \mathrm{m}^{2}$ to meet the operational carbon target of $27 \mathrm{~kg} \mathrm{CO} 2 / \mathrm{m}^{2} / \mathrm{yr}$; a $2.5 \%$ increase in funding. Contrary to HGS (Case Study 3), the introduction of the new government's target was not deemed to be controversial. In fact, the target encouraged the innovative biodiesel Combined Heat and Power (CHP) solution, the first of its kind in a UK school building ${ }^{\mathrm{x}}$. The difference in perception among ProjectCo actors on HGS (Case Study 3) and BWS (Case Study 4) could be explained by the fact that on BWS (Case Study 4) the introduction of the carbon target midway through the process was coupled with the provision of the additional funding, therefore, not necessarily jeopardising ProjectCo's profitability. This is in contrast to HGS (Case Study 3) for which the change of requirement was not reflected in the original Outline Business Case (OBC) and therefore the scheme's funding. While the Local Authority contributed additional funding to the project, the requirement was still deemed to be exhaustive (Case Study 3). Previous innovation-management research have argued that policymakers can encourage private-sector producers to develop new ideas by imposing challenging requirements that are difficult for existing technologies to conform to, thus inducing innovation (Seaden and Manseau, 2001; Blayse and Manley, 2004). However, our findings demonstrate that such mechanisms should be implemented with caution, particularly in relation to current technological and financial constraints. Indeed, the findings suggest that for such mechanisms to be effective in supporting SEI, greater alignment between the innovative sustainable-energy requirement and the allocated budget is necessary. By doing so, ProjectCo actors are more encouraged to bring about environmentally as well as 
economically favourable innovations, or what Porter and van der Linde (1995) termed as 'economically benign environmental innovations'

The limited BSF budget also meant that constant effort was needed by ProjectCo actors to balance the schools' educational requirement and the sustainability requirement (Case Studies 1, 2, and 3). The four schools were increasingly interested in becoming leaders for sustainability among their wider community and demonstrating their commitment to carbon reduction. Sustainability was, however, not high on the schools' agenda, with the four schools' priority fundamentally being their educational requirements. ProjectCo actors expressed the difficulty of balancing the schools' transformational learning aspiration and energy conscious design. On BEC (Case Study 1) and SVC (Case Study 2) the schools' aspiration for large and uplifting social spaces resulted in the schools' area significantly exceeding the area requirements of BB98 (Briefing Framework for Secondary School Projects). This consequently led to higher lighting and heating demands, largely contradicting the energy efficiency objective. On HGS (Case Study 3) the school's reluctance to reduce the number of car parking spaces allocated in their site largely affected the school's overall carbon footprint and restricted the objective to reduce their overall $\mathrm{CO}_{2}$ emission. On SVC (Case Study 2) several sustainability elements were engineered out during affordability negotiations (such as a Virtual Energy Centre). The observed limited interest in sustainable energy among schools represents a challenge to SEI as user commitment is vital for innovations which try to develop radical alternative solutions to realise users' requirements in a more eco-efficient manner (Heiskanen and Lovio, 2007).

In addition to their Output Specification, public-sector actors who procure capital assets rely on governing frameworks that include regulations, standards, and norms to ensure that the facilities delivered conform to the criteria of the specific context. ProjectCo actors across the four case studies agreed that the governing framework was made clear on BSF documentation. ${ }^{\mathrm{xi}}$ However, the study findings pointed out several deficiencies in the governing framework that discouraged ProjectCo 
actors from pursuing SEI (Table 4, UofA.3). This was particularly the case on HGS (Case Study 3), with the rigid design standards that the design needed to adhere to inhibited innovation. This was in relation to the design of the east elevation of the building, which overlooks a busy emergency route. The noise levels permitted by BB93 (School Acoustics) meant that the east elevation of the building had to be completely sealed off and all rooms located on this side of the building (nearly $70 \%$ of the school area) needed to be mechanically ventilated. The design team was increasingly frustrated in that there was no scope within BB93 to allow for any openings in the elevation. This restricted the opportunity to develop innovative solutions that might work in minimising noise levels while maintaining natural ventilation within those rooms. The absence of window openings may also have detrimental effects on educational outcomes given the strong association between pupils' learning progression and the quality and quantity of natural light their classrooms receive (Barrett et al., 2013).

Furthermore, the findings highlighted the inability of the BREEAM requirement to promote SEI and energy efficiency. Under BSF, every newly built and refurbished school was required to achieve at least a "very good" rating, which means scoring points on issues such as health and well-being, energy use, transport, land use and ecology, and pollution. The four Local Authorities depended on BREEAM to specify their environmental sustainability requirement. While BEC (Case Study 1) was specified to BREEAM 'Very Good', SVC (Case Study 2), HGS (Case Study 3), and BWS (Case Study 4) were specified to BREEAM 'Excellent'. Across the four case studies, ProjectCo actors agreed that BREEAM was successful in ensuring a certain level of sustainability. Indeed, on SVC (Case Study 2), the BREEAM 'Excellent' requirement was seen as the main driver for sustainability. The Project Architect argued that without the BREEAM requirement being an important part of the contract, affordability pressures on the Contractor might have resulted in the buildings not achieving the target. This suggests that BREEAM does work to force contractors to ensure a certain level of environmental sustainability. However, ProjectCo actors agreed that BREEAM offered only a limited incentive to achieve exceptional results for energy efficiency and $\mathrm{CO}_{2}$ reduction. Securing a BREEAM "Excellent" rating does not necessarily indicate that the most energy-efficient building was 
achieved, because credits can be scored for issues unrelated to the building performance, such as having consultation at the correct time. BREEAM also alters the strategies adopted by contractors. Contractors may install technologies in order to achieve BREEAM credits, while those technologies are unsuitable, inefficient, not needed, and cannot be used. In fact, the ProjectCo Energy Consultant (Case Study 4) maintained that some contractors would install biomass boilers in order to achieve BREEAM credits, while in reality the contractor would install a small biomass boiler but also a large gas boiler and actually would run the school largely on gas. On HGS (Case Study 3) BREEAM was seen as restricting the development of innovative materials, as it encouraged the use of pre-identified materials from the Green Guide to Specification (BRE, 2009). In addition, while achieving zerocarbon schools may require linking to District Heating Networks, the Project Architect (Case Study 2) pointed out that BREEAM does not recognise off-site renewable energy generation. This calls for a much stronger response than from BREEAM, because no matter how high a project scored, that would not necessarily indicate low-carbon emissions or carbon-neutrality.

\section{Flexibility of the sustainable-energy requirement}

The flexibility and scope for innovation provided by the output-based nature of the sustainable-energy requirement was acknowledged on SVC (Case Study 2), HGS (Case Study 3), and BWS (Case Study 4) (see Table 4, UofA.4). ProjectCo actors agreed that the output-based nature of the requirement allowed the teams' considerable flexibility to suggest innovative solutions to meet the energy requirement. The Local Authorities also benefitted from bidders coming with alternative solutions to achieve it ${ }^{\mathrm{xii}}$.

However, the case-study findings also suggested that the espoused benefits of the output-based nature of the requirement were negated at times by the limited "specificity" of the requirement, increasing uncertainty and leading to misinterpretation of the requirement by ProjectCo actors. Limited specificity resulted from the Local Authorities' provision of a general sustainable-energy requirement 
that did not reflect the sensitivity of its particular context. This was observed on BEC (Case Study 1) and HGS (Case Study 3). For example, On BEC (Case Study 1), the Local Authority's provision of non-specific energy performance standards, such as in the form of the general requirement to 'reduce energy consumption', increased uncertainty and the potential for misinterpretation of the requirement. The requirement also lacked site-specific targets for carbon reduction or on-site renewable energy generation, as the Local Authority planning policy did not require it at the time. The Local Authority actors were seen as 'very broad-concept people' and unable to articulate their requirements. ProjectCo actors thus found it difficult to translate the Local Authority's higher level sustainability objectives into physical solutions to be incorporated into the building. In fact, the output-based nature of the requirement was seen to increase the risk that suggesting high-cost renewable energy technologies might have resulted in the ProjectCo failing to win the bid. The price sensitivity of the public sector clients meant that constant efforts were needed by ProjectCo actors to balance sustainability proposals with the project's financial constraints, so as not to jeopardise affordability, leading to sustainability being somewhat 'compromised'. The findings suggest that output-based requirements may fail to represent the context-sensitive nature of sustainability. In the case of SEI, the newness of the sustainable-energy requirements to firms requires adequate specificity in order to ensure appropriate definition and thus greater understanding of the requirement by the ProjectCo actors.

\section{Incentivisation mechanisms}

Across the case-study projects ( see Table 4, UofA.5) the incentive for the ProjectCo actors to innovate in improved energy performance was dampened by the low weighting of environmental sustainability and energy issues on BSF bid-evaluation criteria (refer to Table 5). The large number of issues involved on BSF bids meant that sustainability and energy issues had a relatively low weighting on BSF bid-evaluation criteria. For example, on SVC (Case Study 2), the ProjectCo main incentive while bidding was to win the contract. Therefore, the team pursued a low-energy design as they felt that it would increase the probability of ProjectCo becoming the preferred bidder. Apart from 
this, there were limited financial incentives for the team to achieve exceptional results for sustainability and energy efficiency. On HGS (Case Study 3), Local Authority representatives were frustrated in that BSF bid-evaluation criteria did not adequately reflect the Local Authority's strong corporate commitment to sustainability. ProjectCo actors on BEC (Case Study 1) and BWS (Case Study 4) also clearly indicated that their incentive to pursue SEI was not particularly driven by the weighting of sustainability in bid evaluation, but by their view of sustainability as a 'winning strategy' to differentiate their bid and a marketing approach to strengthen the company's environmental credentials. On BWS (Case Study 4) the ProjectCo Bid Director also added that it was not the energy performance of the designs that differentiated bids; it was the innovations proposed within the bid that ultimately captured the Local Authority's attention. Indeed, as the study findings suggest, the competitive nature of the PFI design process can encourage innovation, as a differentiating strategy by contractors. However, the low weighting of sustainability and energy issues on BSF PFI bid evaluation may tip the balance in favour of other forms of innovation, rather than SEI.

Finally, an examination of the SEIs implemented across the four case study projects underlines the incremental nature of the innovations implemented. In BEC (Case Study 1) the chimney design was a novel combination of available technologies which were proven in the past to be effective and reliable. This was also the case on HGS's (Case Study 3) where the energy supply strategy utilized a new combination of tried and tested systems. BWS's (Case Study 4) Biodiesel CHP plant was an established technology and was sourced from a well-known German supplier. Across the case study projects, the reliability of the technologies implemented was an important criterion for the ProjectCo as it minimised its risk exposure and reduced the uncertainty associated with the innovation xiii. This suggests that the type of SEIs most likely to be implemented on PFI projects are incremental and exploitative (March, 1991; Slaughter, 1998; Holmqvist, 2004) rather than radical or explorative (Slaughter, 1998; March, 1991; Holmqvist, 2004). PFI seems to be less able to originate SEI, but acts as the 'market' to apply better understood forms of SEI. This signals the important role that construction manufacturing should play in driving SEI as most of the design solutions in PFI are 'off 
the shelf'. The bias of PFI towards incremental innovation, however, restricts the ability of PFI contracts to deliver the government's zero-carbon objectives as the delivery of such substantial reductions in carbon emissions requires more radical innovations (Huesemen, 2003; Enkvist et al., 2008).

\section{Conclusions}

Limited research work has been undertaken on the study of clients' environmental sustainability requirements-management, especially for PFI construction projects. This paper has improved the comprehension of the nature of the clients' sustainable-energy requirements and has provided insights into the prevailing problems associated with the development of clients' requirements and its translation into an innovative sustainable design. In particular the investigation of four new-build PFI school projects has shown that the incentive effects of environmental requirements are often weak in PFI projects. This is particularly so in relation to the requirements' limited specificity and achievability, the inability of requirements such as BREEAM to promote energy efficiency, and the low weighting of environmental sustainability and energy issues on PFI bid-evaluation criteria. Taken together, these results underline the deficient public authority's role in relation to providing the necessary conditions for the effective implementation of PFI as an innovation policy tool for sustainable energy.

The findings contribute to the subject of public procurement of environmental innovation through the PPP and PFI contractual arrangements and have several implications for decision-makers seeking to encourage sustainable-energy innovation in the design-development process. This should prove valuable to both public and private sector actors interested in the delivery of sustainable buildings across the international PFI sector as the project delivery model grows in popularity in emerging 
economies such as those of Nigeria (Taiwo and Tajudeen, 2014) and China (Wang et al. 2012). However, it should be noted that the recommendations made relate specifically to BSF PFI school projects. The recommendations are made based on research findings that need to be confirmed or rejected by further research as representative of all PFI projects.

Above all, the findings identified the need for Local Authorities to ensure that the incentive effects of the sustainable-energy requirements are stronger, particularly in relation to its specificity and achievability. Having technical and market knowledge in the public-sector client's team will help the team formulate innovative targets and requirements. Technical expertise is crucial to precisely define needs, assess new technologies, and interact with the market. Therefore, the capabilities of pubicsector clients' teams should be checked to meet the programme-level environmental sustainability targets and standards. Accurate assessment of current as well as future requirements is paramount, given the infamous weakness of PFI contracts to adequately adapt to future changes in public-sector service requirements during their operational stages (HM Treasury, 2012). Therefore, Local Authorities should ensure that sufficient funding is available to secure the involvement of key internal sustainability and energy expertise in sustainability-requirement identification. The findings also underlined the need for the innovative requirement to be coupled with adequate funding. Thus, the governmental bodies responsible for PFI should ensure that innovative sustainable-energy requirement are clearly reflected in the Public Sector Comparator (PSC) ${ }^{\mathrm{xiv}}$. Indeed, failing to build sustainable energy into the PSC will result in SEI being abandoned as being 'unaffordable'. For instance, if the PSC has taken into account that the scheme must be zero carbon, the allocated budget may encourage ProjectCo actors to bring about innovation for sustainable energy.

In addition, the study identified three key areas of improvements to the governing framework guiding the development of proposals in PFI projects. First, the study indicated the need for both the public and private sectors to adopt a much stronger response than BREEAM, because no matter how high a 
project scored, that would not necessarily indicate low-carbon emissions or carbon-neutrality. An alternative, in the form of the 'Living Building Challenge' programme, may address some of these criticisms (Conseil International du Bâtiment, 2016). The certification requires all mandatory items to be achieved, such as Net Zero Energy, and is based on actual performance over a 12 months period instead of modelled or expected performance (International Living Future Institute, 2012). Moreover, the low weighting of environmental sustainability and energy issues within PFI bid-evaluation criteria needs to be addressed to encourage ProjectCo actors to pursue SEI. Therefore, Local Authorities should raise the profile of environmental sustainability and energy issues in their bid-evaluation criteria to signal to the private sector the reward structure linked with pursuing innovation for sustainable energy.

This explorative study has contributed a picture of the practice of sustainable-energy requirement identification and translation in four PFI school projects and has stimulated a number of questions for future research. In particular, more studies are needed to better understand the relationship between national- and programme-level environmental agendas, organisational strategies, and procurement procedures, as well as in-house capabilities in the public sector and how these factors influence the implementation of environmental innovations in projects. Future studies should also examine refurbishment projects which are likely to assume a large percentage of work within future UK school capital investment programmes, as opposed to new build, the focus of this study. An interesting question also relates to the internal knowledge base of the ProjectCo SPV corporate sponsors and their ability to transfer SEI from their previous expertise into these individual projects e.g. are the ProjectCo bid teams generic and based on their experience of winning previous PFI bids, or do they engage with their corporate experts at an early enough stage to build in truly novel SEI? This is closely related to organisational capability building research (Brady and Davies, 2000, 2004) and warrant further attention from policymakers and researchers. 


\section{References}

Amstel, F. M., Zerjav, V., Hartmann, T., van der Voort, M. C., and Dewulf, G. P. (2015). Expanding the representation of user activities. Building Research \& Information, Vol. 43, No. 2, pp. 144-159.

Anderson, P; Cook, N. and Marceau, J. (2004), Dynamic Innovation Strategies and Stable Networks in the Construction Industry: Implementing Solar Energy Projects in the Sydney Olympic Village, Journal of Business Research, Vol. 57, No. 4, pp. 351-360.

Badi, S. M. and Pryke, S. (2015). 'Assessing the quality of collaboration towards the achievement of Sustainable Energy Innovation in PFI school projects'. International Journal of Managing Projects in Business., Vol. 8, No. 3, pp. $408-440$.

Bahill, A.T. and Dean, F. (1999). Discovering system requirements, in Sage, A.P. (Ed.), Handbook of System Engineering and Management, Wiley-Interscience, New York, pp. 175-219.

Barrett, P. and Sexton, M. (2006). Innovation in small, project based construction firms. British Journal of Management, Vol. 17, No. 4, pp. 331-346.

Barrett, P. and Stanley, C. (1999), Better Construction Briefing, Blackwell Publishing, Oxford.

Barrett, P., Zhang, Y., Moffat, J., \& Kobbacy, K. (2013). A holistic, multi-level analysis identifying the impact of classroom design on pupils' learning. Building and Environment, Vol. 59 (2013), pp. 678-689.

Barlow J. (2000), Innovation and Learning in Complex Offshore Construction Projects, Research Policy, Vol. 29, No. 7-8, pp. 973-989.

Bernard, H. R., Killworth, P., Kronenfeld, D., and Sailer, L. (1984), The problem of informant accuracy: The validity of retrospective data. Annual review of anthropology, Vol.13 (1984), pp.495-517.

Blayse, A. M. and Manley, K. (2004). Key Influences on Construction Innovation, Construction Innovation. Vol. 4, No. 3, pp. 143-154.

Bon, R. and Hutchinson, K. (2000). Sustainable Construction: Some Economic Challenges. Building Research Information, Vol. 28, No. 5-6, pp. 310-314. 
Bossink, A.G. (2004). Managing Drivers of Innovation in Construction Networks. Journal of Construction Engineering and Management, Vol. 130, No. 3, pp. 337-345.

Brady, T and Davies, A. (2000), Organisational Capabilities and Learning in Complex Product Systems: Towards Repeatable Solutions, Research Policy, 29, 7-8, pp. 931-953.

Brady, T and Davies, A. (2004), Building Project Capabilities: From Exploratory to Exploitative Learning, Organization Studies, 25, 9, PP. 1601-1621.

Brandon, P. and Lu, S. L. (2008), Clients driving innovation, Blackwell Publishing Ltd, Oxford, UK.

Bresnen, M. and Marshall, N. (2000). Motivation, Commitment and the Use of Incentives in Partnerships and Alliances, Construction Management and Economics, Vol. 18, No. 5, pp. 587-598.

Building (2008), Skanska lost record $£ 5 \mathrm{~m}$ on failed BSF bid, (5th December 2008), available online: http://www.building.co.uk.

Cabinet Office (2002), The Energy Review: A Performance and Innovation Unit Report, available online: http://www.cabinetoffice.gov.uk.

Clement, S.; Tepper, P.; Acker, H.; Seebach, D.; Geuder, A. and Adell, A. (2009). Driving Energy Efficient Innovation through Procurement: A practical Guide for Public Authorities. The SMART SPP Consortium (www.smart-spp.eu).

Confederation of British Industry (CBI) (2006), Innovation and Public Procurement: A New Approach to Stimulating Innovation, Confederation of British Industry, London.

Conseil International du Bâtiment (2012). CIB Research Roadmap: Sustainable Construction, International Council for Research and Innovation in Building and Contraction, Delft, The Netherlands.

Dair, M. and Williams, K. (2006), Sustainable Land Use: The Influence of Different Stakeholders in Achieving Sustainable Brownfield Development in England, Environment and Planning, Vol. 38, No. 7, pp. 1345-1366.

Darlington, M. and Culley, S. (2004). A model of factors influencing the design requirement. Design Studies, Vol. 25 pp. 329-350. 
Dalpé, R., DeBresson, C. and Xiaoping, H. (1992), The Public Sector as First User of Innovations, Research Policy, Vol.2, No.3, 251-263.

Department for Children, Schools and Families (DCSF) (2007), The Children's Plan, The Stationary Office, London.

Department for Children, Schools and Families (DCSF) (2010). Road to Zero-Carbon, Final Report of the Zero-Carbon Task Force. The Stationary Office, London.

Department for Education (DfE) (2010). Impact on BSF Schools by Local Authority, available on line: http://www.dfe.gov.uk.

Department for Education and Skills (DfES) (2005), Building Schools for the Future, Value for Money Assessment, available online: http://www.bsf.gov.uk.

Department for Education and Skills (DfES) (2004). Building Schools for the Future: A New Approach to Capital Investment. The Stationery Office, London.

Department of Energy and Climate Change (DECC) (2008). Climate Change Act 2008: Impact assessment. The Stationary Office (TSO) for the DECC, London.

Department of Energy and Climate Change (DECC) (2012) Digest of United Kingdom Energy Statistics 2012, Available online: http://bit.ly/2b5LvHK

Department for Environment, Food and Rural Affairs (DEFRA) (2007), Draft Climate Change Bill, DEFRA, HM Government, Available online: http://bit.ly/2aVJ4aI

Department of Trade and Industry (DTI) (2007), Meeting the Energy Challenge, A White Paper on Energy, Department of Trade and Industry, London.

Dewulf, K. R. (2013). Sustainable product innovation: the importance of the front-end stage in the innovation process. In: Coelho D.A (ed.) Advances in Industrial Design Engineering, Intech, Croatia.

Dewick, P. and Miozzo, M. (2004). Networks and Innovation: Sustainable Technologies in Scottish Social Housing. R\&D Management, Vol. 34, No. 3, pp. 323-333. 
Edler, J.; Edquist, C.; Georghiou, L.; Rigby, J.; Hafner, S.; Hommen, L.; Papadakou, M.; Rolfstam, M. and Tsipouri, L. (2005), Innovation and Public Procurement: Review of Issues at Stake, Study for the European Commission, European Commission: Brussels, Belgium.

Edler, J. and Georghiou, L. (2007), Public procurement and Innovation: Resurrecting the Demand Side, Research Policy, Vol. 36, No. 7, pp. 949-963.

Edquist, C. (1998), The ISE Final Report: Scientific Findings and Policy Implications of the "Innovation Systems and European Integration" (ISE) Research Project, European Commission, Brussels, Belgium.

Education Funding Agency (2015), Guidance: PSBP: selected bidders - private finance batches, Available online:https://www.gov.uk/government/publications/psbp-selected-bidders-private-financebatches/psbp-selected-bidders-private-finance-batches.

Edward, P. and Shaoul, J. (2003), Controlling the PFI Process in Schools: a Case Study of the Pimlico Project, Policy and Politics, Vol. 31, No. 3, pp. 371-385.

Eisenhardt, K. M., and Graebner, M. E. (2007). Theory building from cases: opportunities and challenges. Academy of management journal, Vol. 50, No. 1, pp. 25-32.

Enkvist, P.; Naucler, T. and Oppenheim, J. (2008), Business Strategies for Climate Change, The McKinsey Quarterly, No.2.

Environmental Protection Agency (EPA) (2002), Innovating for Better Environmental Results: A strategy to guide the Next Generation of Innovation at EPA, United States Environmental Protection Agency, Washington DC.

Eriksson, P.E. and Westerberg, M. (2010). Effects of Cooperative Procurement Procedures on Construction Project Performance: A conceptual framework, International Journal of Project Management, Vol. 29, No. 2, pp. 197-208.

Flyvbjerg, B. (2006), Five Misunderstandings about Case Study Research, Qualitative Inquiry, Vol. 12, No. 2, pp. 219-245.

Gann, D. and Salter, A. (2000). Innovation in Project-based, Service-enhanced Firms: The Construction of Complex Products and Systems. Research Policy, Vol. 29, No. 7/8, pp. 955-972. 
Gann, D.; Wang, Y. and Hawkins, R. (1998) Do Regulations Encourage Innovation? The Case of Energy Efficiency in Housing, Building Research and Information, Vol. 26, No. 5, pp. 280-296.

Green Building Council Task Group (2014) Building Zero Carbon - The Case for Action, UK Green

Building Council, London, available online: http://www.ukgbc.org/resources/publication

Häkkinen, T., and Belloni, K. (2011). Barriers and drivers for sustainable building. Building Research \& Information, Vol. 39, No. 3, pp. 239-255.

Hansen, K. and Rush, H. (1998). Hotspots in Complex Product Systems: Emerging Issues in Innovation Management. Technovation, Vol 18, No. 8-9, pp. 555-561.

Hartmann, A. (2008), Overcoming Resistance to Innovation: the Integration Champion in Construction. In: Brandon, P. and Lu, S. (eds.) Clients Driving Innovation, Blackwell Publishing, Oxford, pp. $157-166$.

Harwood, T. G., and Garry, T. (2003). An overview of content analysis. The Marketing Review, Vol. 3, No. 4, pp. 479-498.

Haugbølle, K., and Boyd, D. (2013). Clients and Users in Construction: Research Roadmap Report. CIB General Secretariat, Delft, The Netherlands.

Heavisides, B. and Price, I. (2001). Input Versus Output-based Performance Measurement in the NHS: The Current Situation. Facilities, Vol. 19, No. 10, pp. 344- 356.

Heiskanen, E. and Lovio, R. (2007), User Knowledge in Housing Energy Innovation, Proceedings of the Nordic Consumer Policy Conference, Lund University, Sweden.

Higgin, G. and Jessop, N. (1965). Communications in the building industry: the report of a pilot study. Tavistock Publications, London.

HM Treasury (1999). Output Specifications for PFI Projects, A 4P's Guide Summary, Public Private Partnerships Programme, The Stationery Office, London.

HM Treasury (2003), PFI: Meeting the Investment Challenge, The Stationery Office: London.

HM Treasury (2012), A new approach to public private Partnerships, The Stationery Office: London.

HM Treasury (2015). The green book Appraisal and evaluation in central government: Treasury guidance. The Stationery Office: London. 
Hobday, M. (1998). Product Complexity, Innovation and Industrial Organization. Research Policy, Vol 26, No. 6, pp. 689-710.

Holmqvist, M. (2004), Experimental Learning Processes of Exploitation and Exploration Within and Between Organizations: An Empirical Study of Product Development, Organization Science, Vol. 15, No. 1 , pp. $70-81$.

House of Commons (2007). Sustainable Schools: Are We Building Schools for the Future? The Stationery Office, London.

Huesemenn, M (2003), The Limits of Technological Solutions to Sustainable Development, Clean Technology and Environment Policy, Vol. 5, No. 1, pp. 21-34.

International Energy Agency (2015) Renewable Energy Medium Term Market Report 2015: Market Analysis and Forecasts until 2020. Available online: http://bit.ly/2bj7b1d

International Living Future Institute (2012). Living Building Challenge 2.1: A Visionary Path to a Restorative Future, International Living Future Institute, Seattle, WA.

James, S. (2011). Review of Education Capital . DfE, London.

Javed, A.A., Lam, P.T.I. and Zou, P.X.W. (2013). Output-based specifications for PPP projects: lessons for facilities management from Australia. Journal of Facilities Management, Vol. 11, No. 1, pp. 5-30.

Johnson, W. and Medcof, J. (2007), Motivating Proactive Subsidiary Innovation: Agent-based Theory and Socialization Models in Global R\&D, Journal of International Management, Vol. 13, No. 4, pp. $472-487$.

Kadefors, A., Björlingson, E., and Karlsson, A. (2007). Procuring service innovations: Contractor selection for partnering projects. International Journal of Project Management, Vol. 25, No. 4, pp. $375-385$.

Kamara, J.M., Anumba, C.J. and Evbuomwan, N.F.O. (2002). Capturing Client Requirements in Construction Projects, Thomas Telford, London.

Kelly, K. (2008). Going Green, The Challenges and Solutions. Automotive Design and Production, Vol. 120, No. 1, pp. 26-31. 
Kemp, R. and Foxon, T. (2007). Eco-innovation from an Innovation Dynamics Perspective, Deliverable 1 of MEI project (D1), UNU-MERIT, available online: http://www.merit.unu.edu.

Kumaraswamy, M. and Dulaimi, M. (2001). Empowering Innovative Improvements through Creative Construction Procurement. Engineering Construction and Architectural Management, Vol. 8, No. 5/6, pp. 325-334.

Lam, P. T., Chan, E. H., Chau, C. K., and Poon, C. S. (2011). A sustainable framework of "green" specification for construction in Hong Kong. Journal of Facilities Management, Vol 9, No. 1, pp. 16-33.

Leiringer, R. (2003), Technological Innovations in the Context of Public- Private Partnership Projects, PhD Thesis, Royal Institute of Technology, Stockholm, Sweden.

Lenard, D. and Eckersly, Y. (1997). Driving Innovation: the Role of the Client and the Contractor, Report No. 11, Sydney: CII Australia.

Lindahl, G., and Ryd, N. (2007). Clients' goals and the construction project management process. Facilities, Vol. 25, No. 3/4, pp. 147-156.

Livesey, P. (2012), Priority Schol Building Programme, DfE, London.

Mallozzi, C. A. (2009). Voicing the interview: A researcher's exploration on a platform of empathy. Qualitative Inquiry, Vol. 15, No. 6, pp. 1042-1060.

March, J. (1991), Exploration and Exploitation in Organizational Learning, Organization Science, Vol. 2, No. 1, pp. 71-87.

Miles, M. and Huberman, A. (1994), Qualitative Data Analysis, Sage: Thousand Oaks, CA.

Miozzo, M. and Dewick, P. (2002). Building Competitive Advantage: Innovation and Corporate Governance in European Construction. Research Policy, Vol. 31, No. 6, pp. 989-1008.

Nam, C.H. and Tatum, C.B. (1992). Strategies for Technology Push: Lessons from Construction Innovations. Journal of Construction Engineering and Management, Vol. 118, No. 3, pp. 507-524.

Nam, C.H. and Tatum, C.B. (1997). Leaders and Champions for Construction Innovation. Construction Management and Economics, Vol. 15, No. 4, pp. 259-270. 
NAO (National Audit Office) (2009). The Building Schools for the Future Programme: Renewing the Secondary School Estate. The Stationery Office: London.

Newcombe, R (2003). From client to project stakeholders: a stakeholder mapping approach. Construction Management and Economics, Vol. 21, No. 8, pp. 841-848.

Ngowi, A. B. (1998). Is Construction Procurement a Key to Sustainable Development? Building Research and Information. Vol. 26, No. 6, pp. 340-350.

Othman, A.E., Hassan, T.M. and Pasquire, C.L. (2005). Analysis of factors that drive brief development in construction. Engineering, Construction and Architectural Management, Vol. 12 No. 1, pp. 69-87.

Orstavik, F., Dainty, A. R., \& Abbott, C. (Eds.) (2015). Introduction, In: Orstavik, F., Dainty, A. R., \& Abbott, C. (Eds.), Construction Innovation. John Wiley \& Sons, Chichester.

Ozorhon, B. (2012). Analysis of construction innovation process at project level. Journal of Management in Engineering, Vol. 29, No. 4, pp. 455-463.

Partnership for Schools (PfS) (2006). The Competitive Dialogue Procedure. Available online: http://www.partnershipsforschools.org.uk.

Porter, M. and van der Linde, C. (1995). Towards a New Conceptualization of the EnvironmentCompetitiveness Relationship, Journal of Economic Perspectives, Vol. 9, No. 4, pp. 97-118.

Qi, G. Y., Shen, L. Y., Zeng, S. X., and Jorge, O. J. (2010). The drivers for contractors' green innovation: an industry perspective. Journal of Cleaner Production, Vol. 18, No. 14, pp. 1358-1365.

Richardson, G. and Lynes, J. (2007). Institutional Motivations and Barriers to the Construction of Green Buildings on Campus: A Case Study of the University of Waterloo, Ontario. International Journal of Sustainability in Higher Education, Vol. 8, No. 3, pp. 339-354.

Robinson, H. and Scott, J. (2008). Service Delivery and Performance Monitoring in PFI/PPP Projects. Construction Management and Economics, Vol. 27, No. 2, pp. 181-197.

Schumpeter, J. (1980). Theory of Economic Development. Transaction Publishers, New Jersey.

Seaden, G. and Manseau, A. (2001). Public Policy and Construction Innovation, Building Research and Information. Vol. 29, No. 3, pp. 182-196. 
Slaughter, E. S. (1998), Models for Construction Innovation, Journal of Construction Engineering and Management, Vol. 124, No. 3, pp. 226-231.

Slaughter, E. S. (2000). Implementation of Construction innovation. Building Research and Information, Vol 28, No. 1, pp. 2-17.

Smith, P G and Reinersten, D G (1998). Developing products in half the time. Van Nostrand Reinhold, New York.

Sporrong, J., and Bröchner, J. (2009). Public procurement incentives for sustainable design services: Swedish experiences. Architectural engineering and design management, Vol. 5, No. 1-2, pp. 2435.

Stern, N. (2006), Stern Review on the Economics of Climate Change, HM Treasury, London.

Taiwo G. J., and Tajudeen A. B. (2014). Public private partnerships/private finance initiatives for financing infrastructure in public tertiary institutions in Nigeria. Built Environment Project and Asset Management, Vol. 4, No. 2, pp. 199-215.

Tatum, C. (1984). What Prompts Construction Innovation? Journal of Construction Engineering and Management, Vol. 110, No. 3, pp. 311-323.

Tawiah, P. A., and Russell, A. D. (2008). Assessing infrastructure project innovation potential as a function of procurement mode. Journal of Management in Engineering, Vol. 24, No. 3, pp. 173186.

Thalmann, P. (2007), Introduction to this Issue, Energy Policy, Vol. 35, No. 11, pp. 5263-5266.

Tzortzopoulos, P., Cooper, R., Chan, P., and Kagioglou, M. (2006). Clients' activities at the design frontend. Design Studies, Vol.27, No. 6, pp. 657-683.

Ulrich, K. and Eppinger, S. (2000). Product design and development ( $2^{\text {nd }}$ edn). McGraw-Hill, USA.

Winch, G. (1998). Zephyrs of Creative Destruction: Understanding the Management of Innovation in Construction. Building Research and Information, Vol. 26, No. 5, pp. 268-279.

Wang, S., Ke, Y. J., \& Xie, J. (2012). Public-private partnership implementation in China. In: Winch, G., Onishi, M. and Schmidt.S. (Eds.) Taking Stock of PPP and PFI around the World, ACCA, Certified Accountants Educational Trust, London, pp. 29-36. 
Whyte and Sexton (2011). Motivations for innovation in the built environment: new directions for research. Building Research \& Information, Vol. 39, No. 5, pp. 473-482.

Woolner, P., Hall, E., Higgins, S., McCaughey, C., \& Wall, K. (2007). A sound foundation? What we know about the impact of environments on learning and the implications for Building Schools for the Future. Oxford Review of Education, Vol. 33, No. 1, pp. 47-70.

Wilkinson, R. (2002), Monitoring and Evaluation of Public Policies for Educational infrastructure, OECD Programme on Educational Building, International Seminar on Educational Infrastructure, Mexico.

Yin, R. (2014). Case Study Research: Design and Methods, Sage Publications, London.

Yu, A. T., Chan, E. H., Chan, D. W., Lam, P. T., and Tang, P. W. (2010). Management of client requirements for design and build projects in the construction industry of Hong Kong. Facilities, Vol. 28, No. 13/14, pp. 657-672.

Yu, A. T., and Shen, G. Q. (2013). Problems and solutions of requirements management for construction projects under the traditional procurement systems. Facilities, Vol. 31, No. 5/6, pp. 223-237.

Yudelson J. (2008), The Green Building Revolution. Island, Washington, DC.

\footnotetext{
${ }^{\mathrm{i}}$ It should be noted that the PFI consortium were responsible for facility related provision, not for the employment of front line staff such as teachers, doctors and nurses except for some specialised healthcare facilities or prisons.

ii There are about 24,000 state schools in England, 3,500 of which are secondary schools with most of the rest being primary schools. These are owned and managed by England's 150 Local Authorities. In 2002 around 14\% of existing school buildings had been built in the previous 25 years, but about $30 \%$ were more than 50 years old (Wilkinson, 2002). Combined with low levels of investment in previous decades, the age of many school buildings signalled a significant need for investment.
}

iii The BSF programme started in 2003/04 with a series of pathfinder projects. In 2005/06, BSF accounted for roughly $40 \%$ of the DCSF capital investment, $£ 2.2$ billion out of a total of $£ 5.1$ billion. Of the $£ 2.2$ billion for BSF, $£ 1.2$ billion (55.5\%) was allocated to PFI schemes (DfES, 2005). The BSF programme, nonetheless, was withdrawn in 2010 soon after the Coalition government assumed power. The programme was scrutinised for its excessive bureaucracy and inefficiency. And yet, since its introduction in 2004, BSF had been responsible for the complete rebuilding or significant refurbishment of a total of 255 schools, of which 132 were PFI (DfE, 2010). Interestingly, the subsequent introduction of BSF's successor, the 'Priority Schools Building Programme' by the Coalition government in 2012 (Livesey, 2012) and its use of Private Finance 2 (PF2) contracts, a reformed model of PFI, to rebuild 46 schools (Education Funding Agency, 2015) clearly indicates that PFI contracts will continue to be a dominant strategy in the delivery of UK school buildings. iv In the DCSF (2010) Report 'Road to Zero-Carbon, Final Report of the Zero-Carbon Task Force', a 'zero carbon' building
was defined as that with "net zero carbon emissions over the course of a year ... after taking into account (a) energy
consumption and related $\mathrm{CO}_{2}$ emissions of the fixed building services (i.e. heating, ventilation, hot water, lighting, and 
appliances) and (b) energy exports and imports from the development (and directly connected energy installations) to and from centralised energy networks". However, this definition is yet to be finalised, according to the UK Green Building Council Task Group report (2014) titled: ‘Building Zero Carbon - The Case for Action'.

${ }^{v}$ A comparison of the average electricity cost in dollars per kilowatt-hour of different sustainable energy technologies by the International Energy Agency (2015) has shown that geothermal technologies are the most economic energy sources $(\$ 0.05 / \mathrm{kW}-\mathrm{hr})$. Photovoltaic systems are more expensive $(\$ 0.125 / \mathrm{kW}-\mathrm{hr})$ and solar thermals are the most expensive $(\$ 0.24 / \mathrm{kW}-\mathrm{hr})$.

${ }^{\text {vi }}$ For example, an input-based specification for classroom lighting could be stated as "supply and installation of XX light bulbs of XX Watts, and XX light fixtures". On the other hand, an output-based approach to the same requirement could be specified by saying 'classrooms need to be lit to XX quality for XX hours per day. Corridors need to be lit to YY quality for YY hours per day. Electricity consumption of the lighting system installed must be XX\% lower than the current system' (Clement et al, 2009).

vii Local authorities were introduced to BSF in 15 waves, i.e. groups of authorities, based on need. In 2006,14 Local Authorities were invited to take part in the first wave of BSF. By 2009 around 96 Local Authorities had joined the programme.

viii The link between the physical environment and educational attainment remains elusive. While studies such as that of Woolner et al. (2007) have found an association between the physical elements of the school environment (e.g. temperature, lighting and air quality) and pupils' attainment, this was only evident up to the level in which the environment was brought up to a standard that is meeting current regulations. Beyond this, a complex set of factors come into play, e.g. Pedagogical, motivational and socio-demographic, which complicate the link between the learning environment and attainment. In fact, a Government review (James, 2011) has argued that leadership and the quality of teaching have a much more profound effect on pupils' attainment than the environment.

ix The Output Specification on BSF projects was required to follow the standard documentation format provided by Partnership for Schools (PfS), the government body responsible for the delivery of the programme. The Output Specification was fundamentally a large set of documents outlining the client's strategic objectives, facilities' requirements, services' specification, performance requirements, and availability criteria. It also had to include annexes outlining statutory requirements in terms of statutory codes, standards, regulations, policy requirements, and design and construction information, such as site-specific restrictions among others. The Output Specification also included a document outlining school-specific requirements in terms of strategy, vision, design considerations, and accommodation requirements. Often concept design drawings (RIBA Stage B) are also prepared by the Technical Advisors to demonstrate the feasibility of the schemes within the budget's and the site's constraints.

${ }^{x}$ CHP is 'the simultaneous generation of usable heat and power (usually electricity) in a single process' (Department of Energy and Climate Change, 2012: p. 191). According to the Digest of United Kingdom Energy Statistics 2012, the electricity generated by CHP schemes in 2011 was just over $27 \mathrm{TWh}$ which corresponds to about 7.4 per cent of all electricity produced in the UK. In 2011, about 89 per cent of CHP electrical capacity were in the industrial sector and 11 per cent of capacity were in the agricultural, commercial, public administration, residential and transport sectors.

xi The main regulatory frameworks that BSF schools were required to adhere to are as follows: (1) BREEAM schools: The Building Research Establishment's Environmental Assessment Method for school buildings. A point-based system that enables schools to assess the design of new or refurbished buildings in terms of several sustainability considerations such as management, health and well-being, energy use, transport, water, materials, land use and ecology, and pollution. Under BSF, every newly built and refurbished school was required to achieve at least a 'very good' rating; (2) Part Lof the Building Regulations on Energy Conservation: Mandatory minimum standards for new buildings and large refurbishment projects in terms of $\mathrm{CO}_{2}$ emissions from heating and power. Schools procured under BSF were required to be at least $23 \%$ more energy efficient than equivalent buildings built before 2006; (3) Building Bulletin 87 (BB87): Guidelines for Environmental Design in Schools: A Department for Education and Skills (DfES) technical manual that deals with issues such as energy use, ventilation, lighting, and water services in schools. The document outlines standards for energy use in schools, for example, $5 \mathrm{kgC}$ per m² per year for secondary schools; (4) Building Bulletin 90 (BB90): Lighting Design of Schools: A DfES technical manual that provides guidance for architects and engineers in relation to lighting design in the various types of spaces and activities found in schools; (5) Building Bulletin 93 (BB93): Acoustic Design of Schools: A DfES technical manual that sets the standards for noise entering the school, and for how easy it is to hear someone talking in a class. The standards are known to be set high and may restrict natural ventilation for urban schools due to noise caused by open windows; (6) Building Bulletin 98 (BB98): Briefing Framework for Secondary School Projects (Revision of BB82): Recommended area guidelines for new school buildings. It outlines the space requirement for basic teaching, halls, learning resources, staff and administration, storage, dining, and social space. 
xii It should be noted that confidentiality was important and one bidder's solutions or other confidential information was not to be revealed to other bidders without their permission (PfS, 2006). Across the four case studies, the BSF engagement process was seen to be 'intense', 'restricted', 'massively bureaucratic', 'cumbersome', 'time-consuming' and 'frustrating' to both Local Authorities' and ProjectCo actors. Communication was difficult because it needed to be equal and uniform across all bidders. It was also complicated by confidentiality issues and a great deal of sensitivity regarding commercial knowledge. Indeed, the Local Authorities' actors were required to sign several documentations about confidentiality prior to their engagement with bidders.

xiii The risk management standard - ISO 31000:2009 - defines risk as 'the effect of uncertainty on objectives' with uncertainty arising whenever the 'understanding or knowledge of an event, its consequence, or likelihood' is inadequate or incomplete. Risk exposure is defined as the 'extent to which an organization and/or stakeholder is subject to an event' (ISO, 2009).

xiv In the UK, the Value for Money (VfM) assessment for PFI projects is undertaken by using a Public Sector Comparator (PSC), which establishes costs over the operation of the service both through traditional procurement methods and through PFI. Those that show better value by using PFI are endorsed. VfM is defined as 'the optimum combination of whole life costs and quality (or fitness for purpose) to meet user requirements' (HM Treasury, 2003, p. 30). 